\title{
Up to $427 \mathrm{GHz}$ All Optical Frequency Down-Conversion Clock Recovery Based on Quantum-Dash Fabry-Perot Mode-Locked Laser
}

\author{
Marcia Costa e Silva, Alexandra Lagrost, Laurent Bramerie, Mathilde Gay, Pascal Besnard, Michel Joindot, \\ Jean-Claude Simon, Alexandre Shen, and Guan-Hua Duan
}

\begin{abstract}
This paper reports on all optical frequency down conversion clock recovery based on Quantum-Dash Fabry-Perot mode-locked laser diode (QD-MLLD). A first section is dedicated to the generation of a tunable repetition rate pulse source based on a first QD-MLLD. The principle is to select three lines in the QD-MLLD spectrum with a filtering technique; the lines spacing are properly chosen to generate the desired repetition rate. In this paper, a frequency of $427 \mathrm{GHz}$ was reached and observed with an optical sampling oscilloscope. Moreover, an encoded $170.8 \mathrm{GHz}$ pulse source was characterized showing no penalty in comparison with our reference obtained by Optical Time Division Multiplexing (OTDM), which confirms the quality of the optical clock. In a second section, we show a clock frequency down conversion based on a second QD-MLLD, which is optically injected by a pulse source, whose repetition rate is $\mathbf{1 0}$ times higher than its self pulsating frequency. The $42.7 \mathrm{GHz}$ down converted clock is then encoded and analyzed showing no penalty in comparison to a standard 42.7 Gbit/s reference, demonstrating its quality. Finally, in a third section, we demonstrate sub-harmonic clock recovery with a QD-MLLD, when a data stream is injected. We measure a penalty of $0.3 \mathrm{~dB}$ when compared to a standard $42.7 \mathrm{Gbit} / \mathrm{s}$ reference.
\end{abstract}

Index Terms-Clock-recovery, mode-locked lasers, optical communications, quantum dot devices.

\section{INTRODUCTION}

$\mathbf{T}$ HE ever increasing demand for capacity motivates scientists to explore different alternatives in order to increase bit rates in optical communications. The development of high performance, reliable and low-cost devices has been the key for this improvement over the years and nowadays improving some existing devices is one way to achieve this goal. Semiconductor Mode-Locked Laser Diodes (MLLD) appear as a versatile device in optical communication. For several years the use of this kind of laser source has been demonstrated for different applications such as a high repetition rate source [1]-[4], wavelength

Manuscript received June 29, 2010; revised October 12, 2010, December 13, 2010, January 10, 2011; accepted January 16, 2011. This work was supported in part by the ANR-Telecom project PERSYST II, in part by the French Government, in part by the UE FEDER program, and in part by the Brittany Region.

A. Lagrost, L. Bramerie, M. Gay, P. Besnard, M. Joindot, J.-C. Simon are with the Université Européenne de Bretagne and the CNRS Laboratory FOTON, UMR 6082, Enssat, F-22300 Lannion, France (e-mail: Alexandra.Lagrost@enssat.fr).

A. Shen and G.-H. Duan are with Alcatel-Lucent-Thalès 3-5 Laboratory, 91767 Palaiseau, France.

Digital Object Identifier 10.1109/JLT.2011.2108262 tunable transmitter [5], generation of millimeter wave signals [6], and also as an optical clock recovery [7]-[9].

The MLLD based on Quantum Dot and Quantum Dash structures (QD) [10]-[13], brought a remarkable improvement of the optoelectronic properties, owing to the three dimensional carrier confinement leading mainly to a broad gain bandwidth and a low phase noise level [12], [14]. QD lasers are expected to present lower threshold current, lower chirp, higher gain, and higher thermal stability than bulk-based devices or even quantum well (QW) devices [15], [16]. All these improvements in laser structure allowed significant advances in the generation of a train of pulses at high repetition rate [17].

Some important results have been published for passive mode locking regime as the generation of high bit rate pulse train as high as $346 \mathrm{GHz}$ in [18] and the generation of subpicosecond pulses at high repetition rate [19], [13], [20]. In an active mode locking regime, the QD-MLLD has been investigated as a powerful device for different applications in optical telecommunications, as an all optical clock recovery for $40 \mathrm{Gbit} / \mathrm{s}$ [21], [22] and a clock recovery at $40 \mathrm{Gbit} / \mathrm{s}$ for RZ, NRZ and DPSK signals [23], which indicates that this kind of technique can be tested for advanced modulation formats. As far as high bit rate transmissions are concerned, different configurations can be reported: as a $160 \mathrm{Gbit} / \mathrm{s}$ source in a OTDM configuration [24]; as a unique source to generate different wavelength-division-multiplexing channels for access network applications [25]; and as a high repetition rate pulsed signal generator up to $170.8 \mathrm{GHz}$ and higher by a simple spectral filtering method, taking advantage of the wide spectrum of the laser [26].

In this work we present the use of QD-MLLD in an active mode locking regime: as a very high repetition rate source and as a $42.7 \mathrm{GHz}$ down-conversion clock recovery using two QD structures. The devices used in this paper were fabricated by Alcatel-Lucent-Thales III-V laboratory. Fig. 1 depicts the laser structure, which is similar to the one described in [27]. The active region is composed of Quantum Dash layers with InGaAsP Quantum Well in a Fabry-Perot (FP) structure. It is a buried hetero-structure and its FP cavity length is one millimeter, for a Free Spectral Range of $42.7 \mathrm{GHz}$. A temperature probe and a Peltier cooler have been integrated to the chip into a butterfly module. These lasers can be passively or actively mode-locked depending on applications. The optical spectrum is quite flat, with about a $13 \mathrm{~nm}$ width at $10 \mathrm{~dB}$ loss for both studied lasers and is centered at $1555 \mathrm{~nm}$ for the high repetition rate pulse source application and at $1560 \mathrm{~nm}$ for sub-harmonic clock re- 


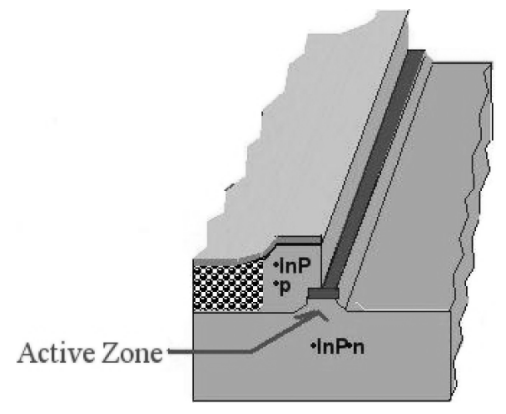

Fig. 1. Schematic sketch of the laser structure.

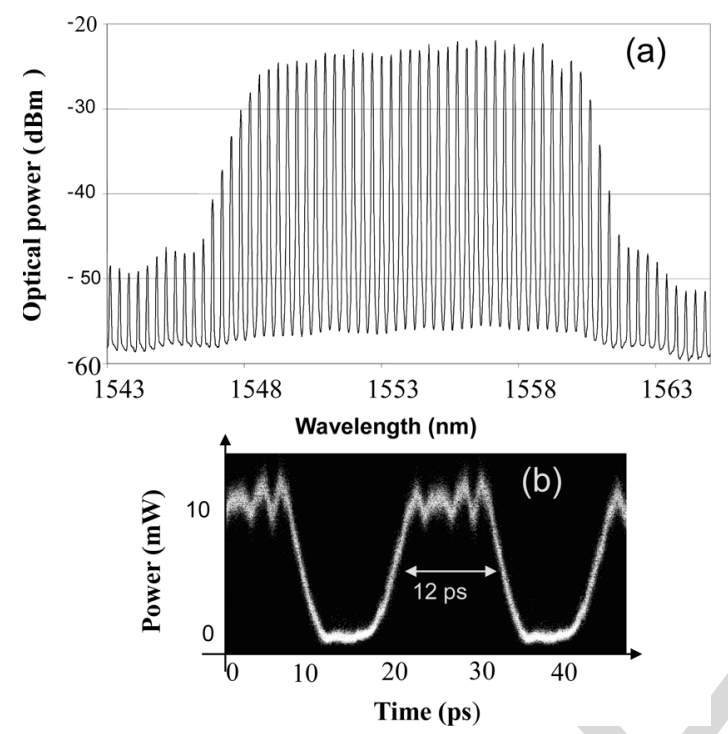

Fig. 2. Optical spectrum and corresponding eye diagram.

covery application. Fig. 2 shows the optical spectrum (a) and the pulse shape (b) for the laser used as a high repetition rate pulse source. The pulse exhibits a large full width at half maximum (FWHM) of about 12 ps. The pulse is not Fourier transform-limited due to the high level of chirp in the laser and to chromatic dispersion in the fiber pigtail.

This paper is divided in three sections. The first one is devoted to the high repetition rate pulse source, using a first QD-MLLD, which can be called a tunable repetition rate pulse source. The principle is to select three lines in the QD-MLLD spectrum with a filtering technique; the line spacing is properly chosen to generate the desired repetition rate. The maximum frequency reachable with this laser is studied. Moreover, the quality of the repetition rate pulse source was assessed through BER measurements.

The second section details how a QD-MLLD can be used as an all optical clock frequency down-conversion. Thanks to the tunable repetition rate source, we assess its capacity to convert a clock at $\mathrm{N} \times 42.7 \mathrm{GHz}$ towards a clock at $42.7 \mathrm{GHz}$. The quality of the encoded down-converted clock at $42.7 \mathrm{GHz}$ is also assessed through BER measurements. Finally, in a third section, we study down-conversion clock recovery in the QD-MLLD, when a data stream is injected.

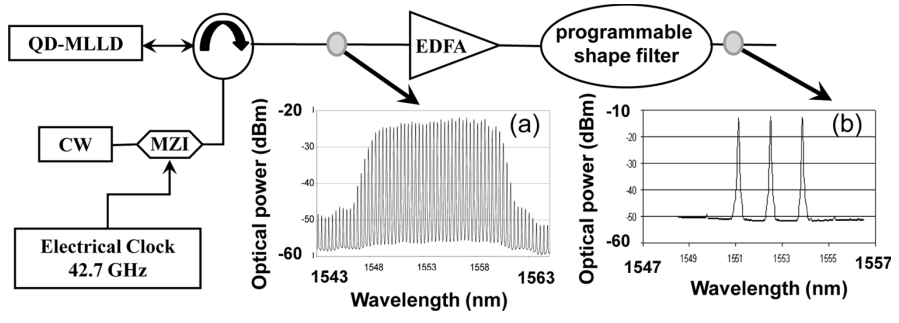

Fig. 3. Experimental setup of the pulse stream generation.

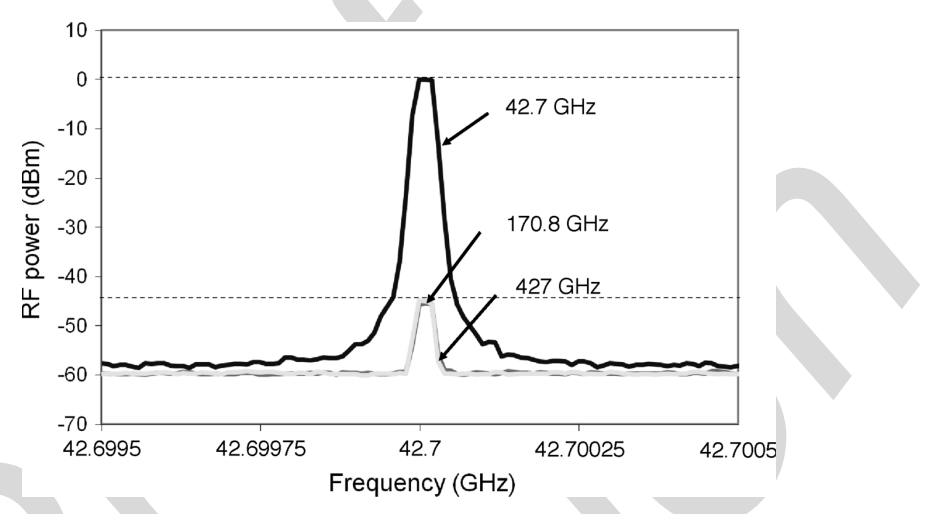

Fig. 4. RF spectrum for generated pulse stream at $42.7 \mathrm{GHz}$ for three different frequencies: $42.7 \mathrm{GHz}, 170.8 \mathrm{GHz}$ and $427 \mathrm{GHz}$.

\section{Tunable Repetition Rate Pulse Source}

This part is dedicated to the generation of repetition rate pulse source at various frequencies by using a Quantum-Dash modelocked laser diode and an optical filter.

\section{A. Experimental Setup}

Fig. 3 depicts the experimental setup. The laser is actively mode-locked by seeding a train of pulses from an optical clock. For that, a RZ 33\% $42.7 \mathrm{GHz}$ optical clock signal is generated at $1535 \mathrm{~nm}$ with a $\mathrm{LiNbO}_{3}$ modulator and is injected inside the cavity of the QD-MLLD module through an optical circulator. Spectrum (a) in Fig. 3 shows the wide spectral comb of the QD-MLLD centered at $1555 \mathrm{~nm}$ with a $13 \mathrm{~nm}$ $(1.6 \mathrm{THz})$ width at $10 \mathrm{~dB}$. The signal of the laser is injected into an optical amplifier and passes through a tunable spectral filter (WaveshaperFinisar ${ }^{\mathrm{TM}}$ ) [28]. Three spectral lines were selected, according to the desired frequency. For example, three lines separated by $341.6 \mathrm{GHz}(8 \times 42.7 \mathrm{GHz})$ are selected as shown in the spectrum (b). We note that the lines do not exhibit residual spurious spectral components at the fundamental clock frequency spacing of the QD-MLLD.

Fig. 4 illustrates the beating spectra at $42.7 \mathrm{GHz}$ for 3 different frequencies generated at: $42.7 \mathrm{GHz}, 170.8 \mathrm{GHz}$ and 427 $\mathrm{GHz}$ measured by means of a high-speed photodiode followed by an electrical spectrum analyzer (ESA), with a resolution bandwidth set to $1 \mathrm{kHz}$ and video bandwidth set to $300 \mathrm{kHz}$. For frequencies greater than $42.7 \mathrm{GHz}, \mathrm{RF}$ component is suppressed by more than $40 \mathrm{~dB}$, confirming the purity of the generated signals. 

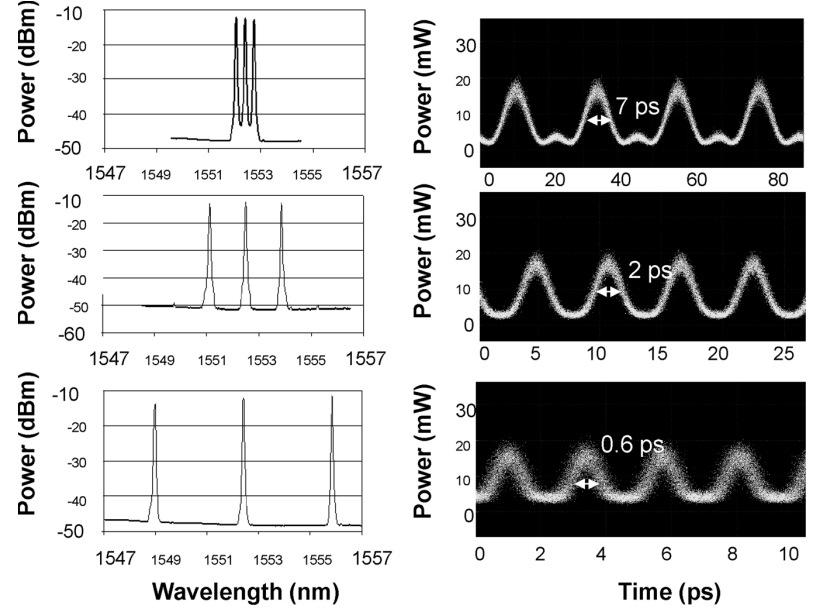

Fig. 5. Generated clock for three different frequencies: $42.7 \mathrm{GHz} ; 170.8 \mathrm{GHz}$ and $427 \mathrm{GHz}$.

\section{B. High Repetition Rate Pulse Source Generation}

The waveform delivered by the tunable repetition rate pulse source is observed using an optical sampling oscilloscope (OSO) with a temporal resolution of one picosecond. An optical spectrum and temporal shape is shown in Fig. 5 for three generated clocks at $42.7 \mathrm{GHz}, 170.8 \mathrm{GHz}$ and $427 \mathrm{GHz}$. The FWHM of pulses are 7, 2 and 0.6 ps respectively. The timing jitter of the tunable repetition rate pulse source seems to be below the oscilloscope resolution. Further investigation of timing jitter was not possible in this work. However, studies with similar laser show a rms jitter bellow 200 fs [21], [29].

Unfortunately, the oscilloscope bandwidth is not sufficient to characterize high repetition rate pulse source. In particular, due to low frequency sampling of the OSO, some unexpected events can not be observed. That is why we devoted the next section to the assessment of the encoded high repetition rate pulse source at $170.8 \mathrm{GHz}$ through bit error rate measurement to confirm the stability of this pulse source.

\section{Bit Error Rate Measurements}

We assessed the clock quality in a back to back experiment, in order to demonstrate the stability of the generated clock signal. We compared the proposed $170.8 \mathrm{GHz}$ generated clock when modulated at $42.7 \mathrm{Gbit} / \mathrm{s}$ with an available reference 170.8 Gbit/s signal obtained by the OTDM method and described in previous work [24].

Fig. 6 illustrates the experimental setup. The $170.8 \mathrm{GHz}$ clock was first encoded at $42.7 \mathrm{Gbit} / \mathrm{s}$ by a Mach-Zehnder intensity modulator (MZI). This does not lead to a true PRBS modulation as each bit of the sequence is repeated four times. However, after demultiplexing for BER analysis, the PRBS sequence is recovered on each tributary. This experiment allows the quality of the optical clock to be assessed. As shown in the upper part of Fig. 6, the modulation at $42.7 \mathrm{Gbit} / \mathrm{s}$ over the signal at 170.8 $\mathrm{GHz}$ will vanish half of the pulses at $170.8 \mathrm{GHz}$. We do the analysis of one undistorted bit out of four at $42.7 \mathrm{Gbit} / \mathrm{s}$. The optical time domain demultiplexer box consists of an electro absorption modulator driven by the clock recovered at $42.7 \mathrm{GHz}$ and a

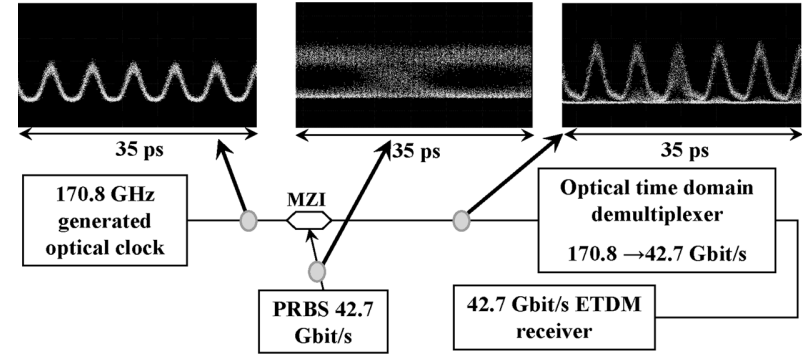

Fig. 6. Experimental setup for data encoding and BER analysis of the 170.8 $\mathrm{GHz}$ generated clock.

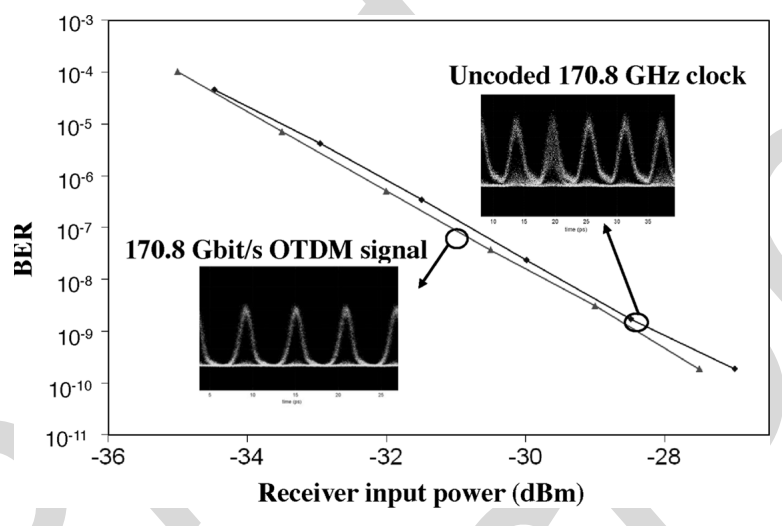

Fig. 7. BER versus receiver input power of the encoded $170.8 \mathrm{GHz}$ generated clock and the $170.8 \mathrm{Gbit} / \mathrm{s}$ OTDM signal.

delay line selecting the tributary to be analyzed in a $42.7 \mathrm{Gbit} / \mathrm{s}$ ETDM receiver. The clock recovery we used is the QD-MLLD as shown in next section. The OTDM $170.8 \mathrm{Gbit} / \mathrm{s}$ signal used as a reference is generated by a $42.7 \mathrm{GHz}$ signal. This last signal is itself obtained from a QD-MLLD and is modulated by a MZI with a $42.7 \mathrm{Gbit} / \mathrm{s} 2^{7}-1$ length pseudo-random binary sequence (PRBS). The $42.7 \mathrm{Gbit} / \mathrm{s}$ data stream is then multiplexed by a bit-rate multiplier (BRM), which multiplies 4 delayed versions of this signal to generate a $170.8 \mathrm{Gbit} / \mathrm{s}$. The choice of the PRBS length is due to the BRM device, which guarantees, thanks to a proper optical delay line in each multiplexing arms, a true PRBS length of $2^{7}-1$ at $170.8 \mathrm{Gbit} / \mathrm{s}$. An encoded $170.8 \mathrm{GHz}$ pulse source and $170.8 \mathrm{Gbit} / \mathrm{s}$ OTDM signal were compared by analyzing the bit error rate.

The BER versus receiver input power is plotted in Fig. 7 for both cases. In the case of the $170.8 \mathrm{GHz}$ generated clock, we don't observe error floor, which confirms the stability of active mode locking of QD-MLLD. Indeed unexpected events would have generated errors. Finally, we observe that the curves of reference (OTDM signal) and of analyzed signal (generated pulse source) are really close (less than $0.2 \mathrm{~dB}$ shift at BER $=10^{-9}$ ). If this experiment is not a full validation of the clock locking on an encoded signal case, this confirms the quality of the optical clock in terms of amplitude noise and timing jitter for telecommunication applications.

\section{All OpticAl Clock Frequency DOWN-CONVERSION}

In this part, we show the ability of the Quantum Dash Fabry-Perot mode locked laser diode to generate a $42.7 \mathrm{GHz}$ clock from a $\mathrm{N} \times 42.7 \mathrm{GHz}$ incident pulse stream [30], [31]. To 


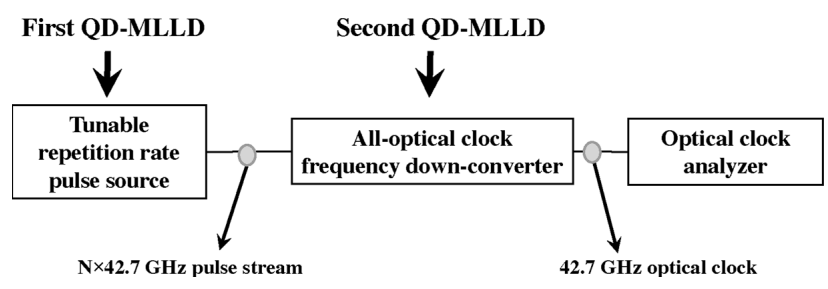

Fig. 8. Block setup for all optical clock frequency down conversion analysis.

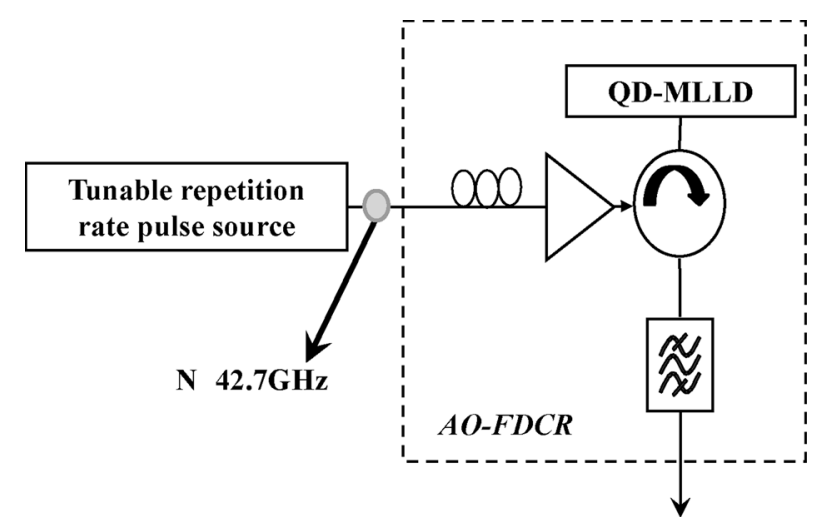

Fig. 9. Experimental setup of the all optical clock frequency down-conversion.

reach this goal, a second QD-MLLD will be used for all optical clock frequency down-conversion.

\section{A. Experimental Setup}

The experimental setup, as shown in Fig. 8 is divided into three blocks. The first one consists of the tunable repetition rate pulse source already described in the first part. We will now describe the two other blocks.

1) All Optical Clock Frequency Down-Conversion: The second block, depicted in Fig. 9, is the all optical clock frequency down-converter. It consists of a second QD-MLLD. The optical signal injected in the laser will lock the laser at a subharmonic frequency.; it is investigated here for very high clock rates. The residual incident pulse stream at $1555 \mathrm{~nm}$ is eliminated by optically filtering the peak emission wavelength around $1560 \mathrm{~nm}$. Mode-locking of the laser is ensured by adjusting the polarization state, the temperature and the current of the laser. The average input power in the QD-MLLD is constant and is around $5 \mathrm{dBm}$, thanks to the polarization-maintaining optical amplifier placed before the QD-MLLD. Finally, when the $\mathrm{N} \times 42.7 \mathrm{GHz}$ pulse stream is injected into the laser cavity, we obtain a $42.7 \mathrm{GHz}$ synchronized down-converted clock at $1560 \mathrm{~nm}$. The clock frequency down-converter robustness to optical input power was not evaluated in this experiment.

Fig. 10 shows the optical spectrum (a) and the pulse shape (b) for the QD-MLLD used as a clock down-converter. The optical spectrum is clearly centred at $1560 \mathrm{~nm}$ and is quite flat, with about $13 \mathrm{~nm}$ width at $10 \mathrm{~dB}$ loss. The pulse exhibits a large FWHM of about 17 ps. Let us notice that at this wavelength range, the OSO specifications are not guaranteed.

In order to assess the all optical frequency down-conversion scheme, the down converted signal is encoded and analyzed.
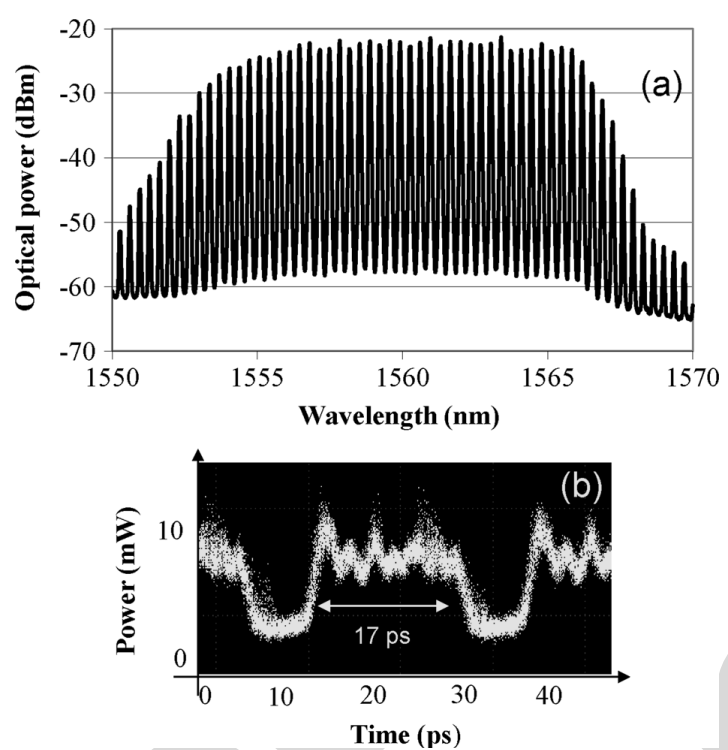

Fig. 10. Optical spectrum and corresponding eye diagram for QD-MLLD used in all optical clock frequency down-converter.

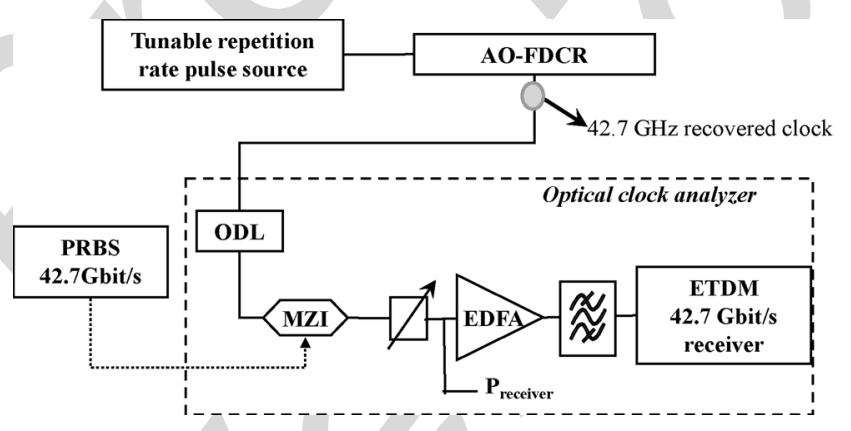

Fig. 11. Experimental setup for the analyzis of the converted clock.

2) Analysis of Recovered Clock: The final step consists in analyzing the optical clock quality with a bit error rate measurement. The experimental setup of this step is shown in Fig. 11. The down-converted signal is modulated at $42.7 \mathrm{Gbit} / \mathrm{s}$ by a $2^{15}-1$ PRBS using a MZI modulator. An optical delay line (ODL), placed before the modulator, ensures that clock and data are in phase. The modulator output signal is sent to an optical receiver for BER measurements, which allows to check whether the down-converted recovery clock is correctly locked. As a matter of fact, if it were not the case, we would have measured an error floor.

\section{B. Results}

Fig. 12 shows the RF spectrum of the beating of the QD-MLLD in the free running regime and in a mode-locked regime (when injected by a signal at $427 \mathrm{GHz}$ ). This signal is measured by a high-speed photodiode followed by an electrical spectrum analyzer (ESA), with a resolution bandwidth of 1 $\mathrm{kHz}$. The free running regime spectrum linewidth is about 20 $\mathrm{kHz}$ showing good accordance with previous measurements performed at Alcatel-Thales III-V Laboratory with such a structure [29]. When QD-MLLD is actively locked, we obtained a $-3 \mathrm{~dB}$ linewidth of $8 \mathrm{kHz}$ in comparison to $20 \mathrm{kHz}$ in 


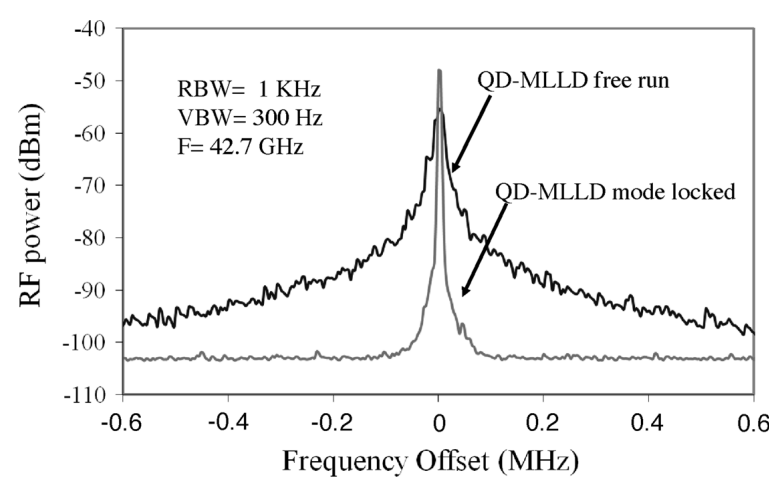

Fig. 12. RF spectrum of the all optical clock frequency down-converter with and without optical mode locking when a signal at $427 \mathrm{GHz}$ is injected.
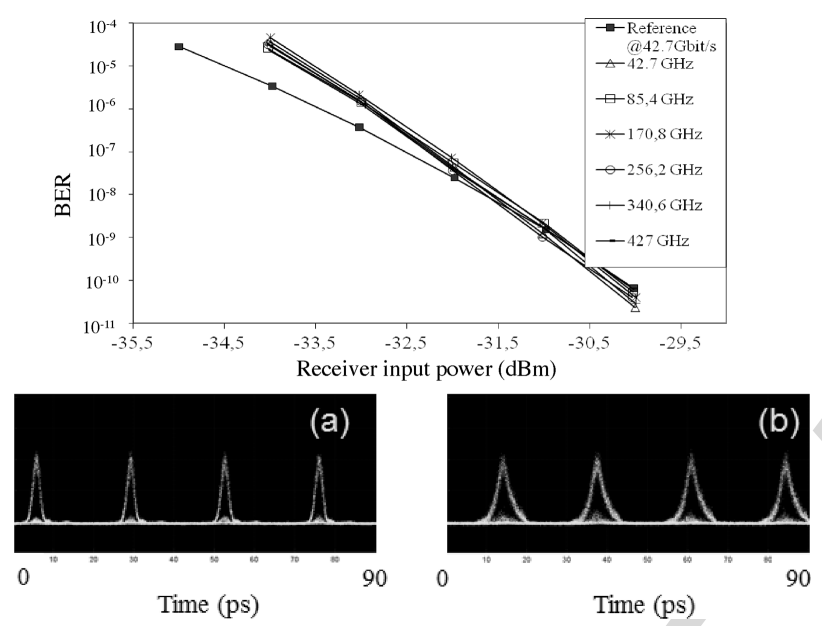

Fig. 13. BER versus the receiver input power for different frequencies of the transmission optical signal. Eye dyagram for (a) $42.7 \mathrm{Gbit} / \mathrm{s}$ reference and (b) $42.7 \mathrm{Gbit} / \mathrm{s}$ clock recovered.

free running regime. This first measurement confirms that the QD-MLLD locks on injected signal.

BER measurements versus the receiver input power are then given in Fig. 13 for 6 different frequencies of the transmitted pulse stream. The reference BER curve is obtained by directly connecting the pulse stream generator output to the optical clock analyzer block.

Fig. 13 shows the eye diagrams of the $42.7 \mathrm{Gbit} / \mathrm{s}$ reference signal (a) and of the encoded down-converted clock (b). Note that the pulsewidth of both signals are sligthly different (5 ps for the recovered clock and $2 \mathrm{ps}$ for the $42.7 \mathrm{Gbit} / \mathrm{s}$ reference). The BER curves in Fig. 13 show that there is no error floor. This confirms that the down-converter is able to lock in the same condition for $\mathrm{N} \times 42.7 \mathrm{GHz}$ incident frequency with a value of $\mathrm{N}$ as large as 10 . Moreover, we obtain no penalty for BER less than $10^{-8}$. For BER higher than $10^{-8}$, penalty appears, this is probably due to slight differences in the temporal shape of both signals.

We note that, as shown previously in the paper, spurious lines of the incident signal are suppressed by more than $40 \mathrm{~dB}$, ensuring that there is no sub-harmonic synchronization of the down-converter at the original clock frequency.

This sub-synchronization at high frequency can be explained by the strong correlation between the phases of the laser modes.

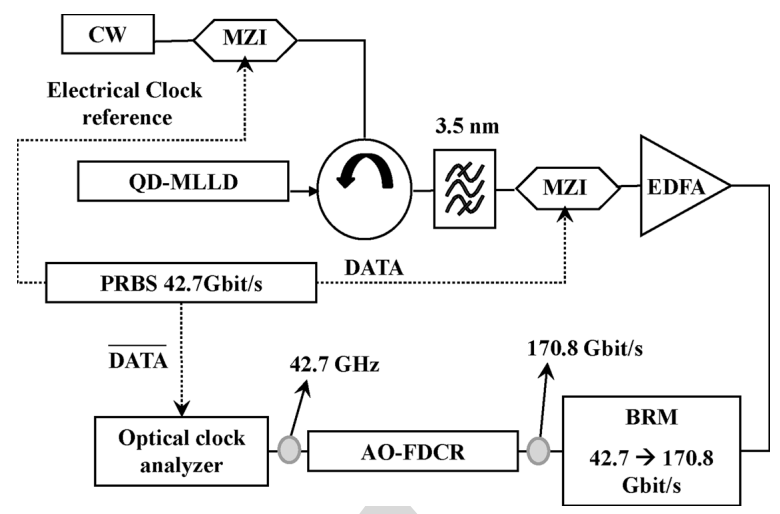

Fig. 14. Experimental setup of the AO-FDCR used as a clock recovery of an OTDM $170.8 \mathrm{Gbit} / \mathrm{s}$.

The strong phase correlation is due to the enhanced four-wavemixing (FWM) in this QD structure [29]. This non-linear effect appears to be the major phenomenon leading to the modelocking of the QD laser [32]. Consequently the $\mathrm{N} \times 42.7 \mathrm{GHz}$ signal modulates the gain section of the QD-MLLD. We assume that this modulation locks in phase the spectrum lines spaced by $\mathrm{N} \times 42.7 \mathrm{GHz}$. Thanks to FWM, all spectrum lines of the laser are afterward locked in phase. Our experimental results demonstrate the possibility to lock the QD-MLLD with an injected signal modulated at 10 times its own frequency.

\section{All Optical Frequency DOWN-CONVERsion Clock RECOVERY}

The principle of clock recovery using a long cavity Fabry Perot Mode Locked multimode laser was studied in [33] and at a subharmonic frequency in [34], [35]. In this section, we characterize the quality of the down-converter when a data stream is injected into the device instead of a clock signal as studied in the previous section. We thus now call the device an All Optical Frequency Down-conversion Clock Recovery (AO-FDCR). This experiment was performed with the two bit rates available in this work: 42.7 and $170.8 \mathrm{Gbit} / \mathrm{s}$.

\section{A. Experimental Setup}

Fig. 14 shows the experimental setup. An electrical clock at 42.7 GHz drives all the system and visualization equipment. The first QD-MLLD generates a 1.5 ps pulse stream at $42.7 \mathrm{GHz}$ modulated through a MZI modulator at $42.7 \mathrm{Gbit} / \mathrm{s}$ with a PRBS sequence. For the case of $170.8 \mathrm{Gbit} / \mathrm{s}$, a BRM is inserted for the OTDM stage. A $2^{7}-1$ sequence was used at $170.8 \mathrm{Gbit} / \mathrm{s}$ (due to the BRM limitation as explained earlier in the paper). The generated data stream is then inserted into the AO-FDCR block and the recovered clock is analyzed in the optical clock analyzer described in the last section.

\section{B. BER Measurements}

BER versus receiver input power is plotted in Fig. 15. The two triangle curves correspond to results obtained in the previous experiment when a pulse stream is injected. The two other curves correspond to BER results when a data stream is injected. A penalty of only $0.3 \mathrm{~dB}$ for a BER of $10^{-9}$ is observed in the case of data stream injection in comparison to pulse stream injection. 


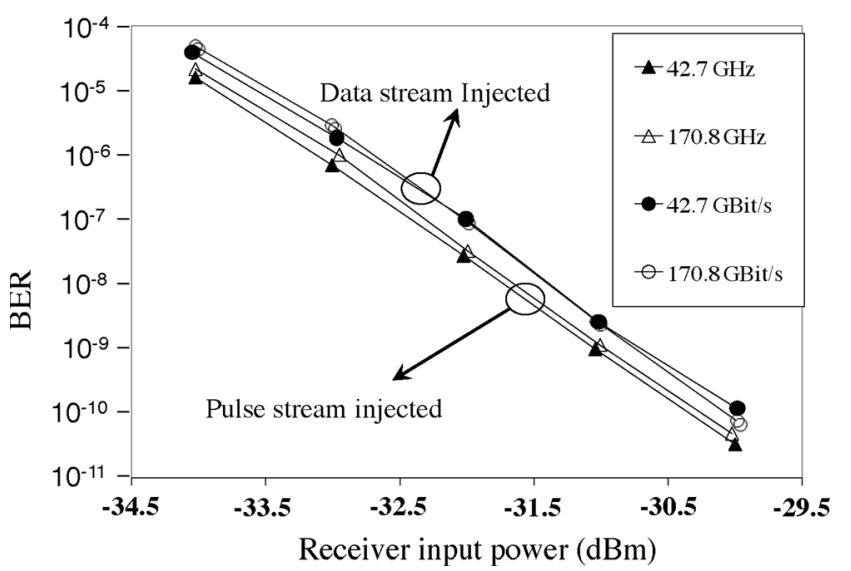

Fig. 15. BER versus receiver input power of encoded optical clock recovery with different input signals: the pulse stream (triangles) or the data stream (circles).

Moreover, 42.7 and $170.8 \mathrm{Gbit} / \mathrm{s}$ curves are superposed showing that the clock recovery quality does not depend on the bit rate. We want to notice here that no phase jump is observed on the recovered clock when it is properly locked. A possible explanation is the really narrow linewidth of some $\mathrm{kHz}$ of this laser [29], [9], thus indicating a strong correlation between modes. It is believed that this strong phase correlation is due to the enhanced four wave-mixing in this QD structure, due to the short lifetime of the electrons at the excited state in the conduction band. However it is not possible to know upon which $42.7 \mathrm{Gbit} / \mathrm{s}$ tributary of the $170.8 \mathrm{Gbit} / \mathrm{s}$ signal, the AO-FDCR locks. In an optical demultiplexing application case, this would imply the use of a Multiple-Input Multiple-Output (MIMO) technique to properly address each OTDM channel at the output receiver.

This experiment thus validates the use of this kind of laser as a clock recovery with data stream up to $170.8 \mathrm{Gbit} / \mathrm{s}$.

\section{CONCLUSION}

In the first section of this paper, we have shown experimentally the potential of QD-MLLD for the realization of a high repetition rate source. Thanks to a spectrum filtering technique, we generated a tunable repetition rate pulse source up to $427 \mathrm{GHz}$. We have investigated the quality of $170.8 \mathrm{GHz}$ pulsed source through BER measurement showing no penalty in comparison to a $170.8 \mathrm{Gbit} / \mathrm{s}$ OTDM signal. These results confirm the ability of the QD-MLLD to be used as a high repetition rate source for telecommunication applications. The repetition rate of this source is only limited by it's spectrum bandwith; $1.2 \mathrm{THz}$ optical source was shown in our previous work [26].

In the second section we performed all optical clock downconversion using QD-MLLD showing the possibility to lock the QD-MLLD with an injected signal modulated at 10 times its own frequency. The quality of the down-converted clock is analyzed through BER measurements: no penalty is observed for BER less than $10^{-8}$. Finally, in all optical down-conversion clock recovery section, we have measured a slight penalty of 0.3 $\mathrm{dB}$ when a data stream is injected. These results show the potential of QD-MLLDs to perform both clock recovery and frequency down-conversion functions. QD-MLLDs could be key components for future 400 Gigabit Ethernet networks.

\section{REFERENCES}

[1] S. Arahira and Y. Ogawa, "160 Gb/s OTDM signal source with 3R function utilizing ultrafast mode-locked laser diodes and modified NOLM," IEEE Photon. Technol. Lett., vol. 17, no. 5, pp. 992-994, May 2005.

[2] U. Feiste, R. Ludwig, C. Schubert, J. Berger, C. Schmidt, H. G. Weber, B. Schmauss, A. Munk, B. Buchold, D. Briggmann, F. Kueppers, and F. Rumpf, "160 Gbit/s transmission over $116 \mathrm{~km}$ field-installed fibre using $160 \mathrm{Gbit} / \mathrm{s}$ OTDM and $40 \mathrm{Gbit} / \mathrm{s}$ ETDM," Electron. Lett., vol. 37, pp. 443-445, 2001.

[3] R. Ludwig, S. Diez, A. Ehrhardt, L. Kuller, W. Pieper, and H. Weber, "A tunable femtosecond modelocked semiconductor laser for applications in OTDM-systems," IEICE Trans. Electron., vol. E81-C:2, pp. 140-145, 1998.

[4] J.-L. Auge, M. Cavallari, M. Jones, P. Kean, D. Watley, and A. Hadjifotiou, "Single channel 160 GBits/s OTDM propagation over $480 \mathrm{~km}$ of standard fiber using a $40 \mathrm{GHz}$ semiconductor mode-locked laser pulse source," in Proc. Optical Fiber Communications (OFC), 2002.

[5] [Page numbers?] M. M. Mielke, G. A. Alphonse, and P J. Delfyett, "High bit rate and reduced noise multiwavelength modelocked semiconductor lasers," in Ultrafast Electronics and Optoelectronics, Technical Digest, 2003.

[6] [Page numbers?] T. Ohno, F. Nakajima, T. Furuta, and H. Ito, "A 240-GHz active modelocked laser diode for ultra-broadband fiber-radio transmission systems," in Proc. Optical Fiber Commun. Conf. Expo. Nat. Fiber Optic Eng. Conf. Tech. Dig., 2005.

[7] [Issue number and month?]S. Arahira, S. Sadaki, K. Tachibana, and Y. Ogawa, "All-optical 160-Gbits/s clock extraction with a mode-locked laser diode module," IEEE Photon. Technol. Lett., vol. 16, pp. 1558-1560, 2004.

[8] [Issue number and month?]Н. Tsuchida, "160 Gbits/s optical clock recovery using a regeneratively mode-locked laser diode," IEEE Photon. Technol. Lett., vol. 18, pp. 1687-1689, 2006.

[9] [Page numbers?] T. Ohno, K. Sato, T. Shimizu, T. Furuta, and H. Ito, "40-GHz optical clock recovery from a 160-Gbit/s optical data stream using a regeneratively mode-locked semiconductor laser," in Proc. ECOC, 2002.

[10] [Issue number and month?] Kirstaedter, N. N. Ledentsov, Z. Alferov, P. Kopev, and V. Ustinov, "InGaAs-GaAs quantum-dot lasers," IEEE J. Sel. Topics Quantum Electron., vol. 3, pp. 196-205, 1977.

[11] X. Huang, A. Stintz, H. Li, L. Lester, J. Cheng, and K. Malloy, "Passive mode-locking in $1.3 \mu \mathrm{m}$ two-section In-As quantum dot lasers," Appl. Phys. Lett., vol. 78, no. 19, pp. 2825-2827, May 2001.

[12] E. U. Rafailov, M. A. Cataluna, and W. Sibbett, "Mode-locked quantum-dot lasers," Nature Photonics, vol. 1, p. 395, 2007.

[13] M. Thompson, A. Rae, M. Xia, R. Penty, and I. White, "InGaAs quantum-dot mode-locked laser diodes," IEEE J. Sel. Topics Quantum Electron., vol. 15, no. 3, pp. 661-672, May 2009.

[14] A. Kovsh, I. Krestnikov, D. Livshits, S. Mikhrin, and J. Weimert, "Quantum dot laser with $75 \mathrm{~nm}$ broad spectrum of emission," Opt. Lett., vol. 32, pp. 793-795, 2007.

[15] [Issue number and month?]F. Lelarge, B. Dagens, J. Renaudier, R. Brenot, A. Accard, F. van Dijk, D. Make, O. L. Gouezigou, J.-G. Provost, F. Poingt, L. J. O. Drisse, E. Derouin, B. Rousseau, F. Pommereau, and G.-H. Duan, "Recent advances on InAs/InP quantum dash based semiconductor lasers and optical amplifiers operating at $1.55 \mu \mathrm{m}$," IEEE J. Sel. Topics Quantum Electron., vol. 13 , p. $111,2007$.

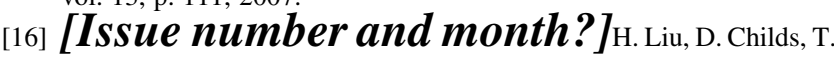
Badcock, K. Groom, I. Sellers, M. Hopkinson, R. Hogg, D. Robbins, D. Mowbray, and M. Skolnick, "High-performance three-layer 1.3- $\mu \mathrm{m}$ InAs-GaAs quantum-dot lasers with very low continuous-wave roomtemperature threshold currents," IEEE Photon. Technol. Lett., vol. 17, pp. 1139-1141, 2005.

[17] H. Schmeckebier, G. Fiol, C. Meuer, D. Arsenijevi, and D. Bimberg, "Complete pulse characterization of quantum-dot mode-locked lasers suitable for optical communication up to $160 \mathrm{Gbit} / \mathrm{s}$," Opt. Exp., vol. 18 , pp. 3415-3525, 2010

[18] K. Merghem, A. Akrout, A. Martinez, G. Aubin, A. Ramdane, F. Lelarge, and G.-H. Duan, "Pulse generation at $346 \mathrm{GHz}$ using a passively mode locked quantum-dash-based laser at $1.55 \mu \mathrm{m}$," Appl. Phys. Lett., vol. 94, p. 021107, 2009. 
[19] [Page numbers?]R. Maldonado-Basilio, S. Latkowski, and P. Landais, "720-fs pulse generation with $40 \mathrm{GHz}$ passively-mode locked quantum-dash Fabry-Perot laser," in Proc. ECOC, 2009.

[20] Z. Lu, J. Liu, P. Poole, S. Raymond, P. Barrios, D. Poitras, G. Pakulski, P. Grant, and D. Roy-Guay, "An L-band monolithic InAs/InP quantum dot mode-locked laser with femtosecond pulses," Opt. Exp., vol. 17, no. 16, pp. 13 609-13 614, 2009.

[21] [Page numbers?]J. Renaudier, B. Lavigne, M. Jourdan, P. Gallion, F. Lelarge, B. Dagens, A. Accard, O. Legouezigou, and G.-H. Duan, "First demonstration of all optical clock recovery at $40 \mathrm{GHz}$ with standard-compliant jitter characteristics based on a quantum-dots self-pulsating semiconductor laser," in Proc. ECOC, 2005.

[22] [Issue number and month?] . Roncin, A. O'Hare, S. Lobo, E. Jacquette, L. Bramerie, P. Rochard, Q.-T. Le, M. Gay, J.-C. Simon, A. Shen, J. Renaudier, F. Lelarge, and G.-H. Duan, "Multi-data-rate system performance of a $40-\mathrm{GHz}$ all-optical clock recovery based on a quantum-dot Fabry-Perot laser," IEEE Photon. Technol. Lett., vol. 19, pp. 1409-1411, 2007.

[23] X. Tang, J. C. Cartledge, A. Shen, A. Akrout, and G.-H. Duan, "Low-timing-jitter all-optical clock recovery for 40 Gbits/s RZ-DPSK and NRZ-DPSK signals using a passively mode-locked quantum-dot Fabry-Perot semiconductor laser," Opt. Lett., vol. 34, pp. 899-901,

[24] [Page numbers?] M. CostaeSilva, H. Ramanitra, M. Gay, L. Bramerie, S. Lobo, M. Joindot, J. Simon, and A. S. et G.-H. Duan, "Wavelength tunably assessment of a $170 \mathrm{Gbit} / \mathrm{s}$ transmitter using a quantum dash Fabry Perot mode-locked laser," in Proc. ECOC, 2009.

[25] [Page numbers?]Q. T. Nguyen, L. Bramerie, G. Girault, O. Vaudel, P. Besnard, J.-C. Simon, A. Shen, G.-H. Duan, and C. Kazmierski, " $16 \times 2.5 \mathrm{Gbit} / \mathrm{s}$ downstream transmission in colorless WDM-PON based on injectionlocked Fabry-Perot laser diode using a single quantum dash mode-locked Fabry-Perot laser as multi-wavelength seeding source," in Proc. OFC, 2009.

[26] [Page numbers?]A. Lagrost, M. Gay, M. CostaeSilva, L. Bramerie, S. LaRochelle, Y. Kim, P. Besnard, and A. S. et G.-H. Duan, "Optical clock generation at $170 \mathrm{GHz}$ from a $42.5 \mathrm{GHz}$ Quantum dash Fabry Perot actively mode-locked laser filtered by a tunable multi-line notch filter," in Proc. CLEO, Postdeadline Section, Munich, Germany, 2009

[27] [Page numbers?]A. Shen, J.-G. Provost, F. Blache, H. Gariah, F. Mallicot, O. Legouezigou, A. Accard, F. Poingt, L. Legouezigou, F. Pommereau, B. Rousseau, F. Lelarge, and G.-H Duan, "Nearly Fourier-transform limited tunnel injection quantum dash mode-locked Fabry-Perot laser module for tuneable pulse generation," in Proc. ECOC, 2007.

[28] [Page numbers?]G. Baxter, S. Frisken, D. Abakoumov, H. Zhou, I. Clarke, A. Bartos, and S. Poole, "Highly programmable wavelength selective switch based on liquid crystal on silicon switching elements," in Proc. OFC, 2006.

[29] [Issue number and month?]J. Renaudier, В. Lavigne, P. Gallion, and G.-H. Duan, "Study of phasenoise properties and timing jitter of $40-\mathrm{GHz}$ all-optical clock recovery using self-pulsating semiconductor lasers," IEEE Photon. Technol. Lett., vol. 24, pp. 3734-3742, 2006.

[30] [Page numbers?] M. C. e Silva, A. Lagrost, L. Bramerie, M. Gay, P. Besnard, M. Joindot, J. C. Simon, A. Shen, and G. Duan, "Up to $425 \mathrm{GHz}$ all optical frequency down-conversion clock recovery based on quantum dash Fabry-Perot mode-locked laser," in Proc. OFC, San Diego, 2010.

[31] [Page numbers?]J. C. Cartledge, X. Tang, M. Yanez, A. Shen, A. Akrout, and G.-H. Duan, "All-optical clock recovery using a quantum-dash Fabry-Perot laser," in Proc. IEEE Topical Meeting Microw. Photon. (MWP), 2010.

[32] C. Gosset, K. Merghem, A. Martinez, G. Moreau, G. Patriarche, G. Aubin, A. Ramdane, J. Landreau, and F. Lelarge, "Subpicosecond pulse generation at $134 \mathrm{GHz}$ using a quantum-dash-based Fabry-Perot laser emitting at $1.56 \mu \mathrm{m}$," Appl. Phys. Lett., vol. 88, p. 241105, 2006.

[33] [Issue and month?] Y. Yang, Y. J. Wen, A. Nirmalathas, H. F. Liu, and D. Novak, "Optical clock recovery at line rates via injection locking of a long cavity Fabry-Perot laser diode," IEEE Photon. Technol. Lett., vol. 16, pp. 1561-1563, 2004.
[34] R. Ludwig, A. Ehrhardt, W. Pieper, E. Jahn, N. Agrawal, H.-J. Ehrke, L. Kuller, and H. G. Weber, " $40 \mathrm{Gbit} / \mathrm{s}$ demultiplexing experiment with $10 \mathrm{GHz}$ all-optical clock recovery using a mode-locked semiconductor laser," Electron. Lett., vol. 32, pp. 327-329, 1996.

[35] [Page numbers?]K. Yoneyama, R. Yokoyama, S. Ishii, S. Yamashita, H. Hashimoto, H. Kurita, T. Shimizu, I. Ogura, and H. Yokoyama, "Error-free $40 \mathrm{Gbit} / \mathrm{s}$ OTDM transmission and all-optical demultiplexing with nonlinear optic functional devices based on modelocked laser diodes," in Proc. ECOC, 1998.

Marcia B. Costa e Silva was born in Recife, Brazil. She received the electronic engineer degree from the Federal University of Pernambuco, Recife, Brazil, in 1998, the M.S. degree from the University of Campinas (UNICAMP), Campinas, Brazil, in 2000, and the Ph.D. degree from the Pontifical Catholic University of Rio de Janeiro, Brazil, in 2004.

In 2004, she was a Fellow with Physical Departments, Federal University of Pernambuco, Recife, Brazil. From 2005 until 2008 she was a Postdoctoral Researcher with TELECOM ParisTech, Paris, France. Since 2009 she has been s a Research Engineer at PERSYST plateform at CNRS-FOTON (ENSSAT, Universisty of Rennes I), Lannion, France. She has authored or coauthored several technical papers in optical communications area.

Alexandra Lagrost was born in France in 1983. She received the M.S. degree in physics from the University of Rennes 1, France, in September 2006, graduating from the engineering school ENSSAT, at Lannion, in Optronics. She received the Ph.D. degree in May 2010 from CNRS-FOTON, ENSSAT, University of Rennes 1 , France, on the possibilities offered by news fibers, such as high non-linear fibers, for the realization of lasers that will be used for transmission systems at $160 \mathrm{Gbits} / \mathrm{s}$.

She realizes fiber Bragg grating, fabricated thanks to two journey at University Laval (Quebec), used as filter to generate optical clocks up to $1.4 \mathrm{THz}$. She has authored or coauthored several technical papers in optical communications area.

Laurent Bramerie was born in France in 1974. He received the opto-electronic engineering degree and the Ph.D. degree from ENSSAT, University of Rennes I, France, in 1999 and 2004, respectively.

He worked two years in Corvis, Lannion, France, a system vendor making ultra-long haul $10 \mathrm{~Gb} / \mathrm{s}$ DWDM systems; in Corvis he was the technical expert on ultra-long haul $40 \mathrm{~Gb} / \mathrm{s}$ DWDM systems. He was hired in 2003 at CNRSFOTON, ENSSAT, Universisty of Rennes I, France, to work on the PERSYST platform which is a public research platform offering testbeds for $40 \mathrm{~Gb} / \mathrm{s}$ and $10 \mathrm{~Gb} / \mathrm{s}$ optical telecommunications systems open to private companies and academic laboratories. He is now research engineer at CNRS-FOTON, where he is the technical manager of the PERSYST platform. He has co-authored approximately 60 papers or communications, including 2 invited conferences and 3 post-deadline papers.

Mathilde Gay received the Ph.D. degree <FROM WHICH INSTITUTION?> on the investigation of the impact of optical regeneration on high bit rate optical transmission systems at 10 and $40 \mathrm{Gbit} / \mathrm{s}$ in February 2006.

She works as a Research Engineer at CNRS FOTON, ENSSAT, University of Rennes I, France, on the PERSYST platform where she has the responsibility of international relations. She is the author or coauthor of about 90 papers in journals or international conferences with a selection process, of two invited papers.

Pascal Besnard received the Ph.D. degree in physics from ENSSAT, University of Rennes I, France, in 1991.

He spent one year as postdoctoral researcher at the Ontario Lightwave and Laser Research Center, Toronto, ON, Canada. He then moved to Enssat, Lannion, France, where he is a Professor. He has been in charge of the Optronics department of Enssat for six years. Since 2009, he has been Deputy Director General of Enssat, in charge of international relations and research. He is at the head of the Laser Physics Group at the CNRS Laboratory FOTON since 2000. His principal research interests include laser physics, optical injection, optical feedback, coherent source and mode-locked lasers for semiconductor and fiber 
technology for optical telecommunication and sensor applications. He is author or coauthor of more than 50 papers, 9 invited papers, 80 oral communications, 50 posters and holds two patents. He has been the scientific coordinator of the book Lasers and Applications, Fifty Years After Its Invention (Hermès, 2010).

Michel Joindot (M'84-SM'93) graduated from Ecole Polytechnique Paris, France, in 1967 and Ecole Nationale Supérieure des Télécommunications Paris, France, in 1970.

He was with CNET, now France Telecom R\&D, working successively on millimeter waveguide, radio systems and communications (modulation, equalization, synchronisation) and after 1990 on optical transmission and transport networks. He has been in position of member of the technical staff, in the fields of optical transmission and digital communications. Between 1984 and 1992 , he has been in charge of the Ph.D. level in signal processing and digital communications at the University of Rennes 1 . Since December 2006, he has been with CNRS-FOTON, ENSSAT, University of Rennes 1, France, where he works about optical functions and systems.

Jean-Claude Simon received the Doctorat d'Etat degree from Universite de Nice in 1983. From 1975 to 1998 he was with CNET, the research centre of the French PTT (now France Telecom R\&D) as a researcher in the field of semiconductor optical amplifiers and non-linear optical signal processing, principally $2 \mathrm{R}$ and 3R all-optical regeneration.

In 1999 he moved to ENSSAT, graduate school of University of Rennes 1, as a Full Professor in optoelectronics. He is presently director of FOTON, a research laboratory associated with CNRS. He has authored or co-authored ap- proximately 200 journal and conference papers including some 25 invited presentations, 10 patents, and 3 book chapters. He has contributed to European research programs (RACE 1027, ESPRIT 3 MOSAIC, ACTS KEOPS, NoE ePIXnet and FP7 Copernicus).

Dr. Simon is a member of the European Management Committee of the European Conference on Optical Communication (ECOC). He isa recipient of the Fabry-de Grammont award from the French Optical Society.

Guang-Hua Duan (S'88-M'90-SM'01) was born in Hubei Province, China, on January 23, 1964. He received the B.E. degree from Xidian University, Xi' an, China, in 1983 and the M.E. and Doctorate degrees, both from the Ecole Nationale Supérieure des Télécommunications (ENST), Paris, France, in 1987 and 1991, respectively, all in applied physics.

He was habilitated to direct research by the Universite de Paris-Sud, Paris, France, in 1995. He is now the Leader of the team "advanced photonic components" within Alcatel Thales III-V Laboratory, Marcoussis, France, with research activities on photonic crystals, advanced semiconductor lasers, optical amplifiers, and functional optoelectronic subsystems for core and metro networks. He lectures in the fields of electromagnetism, optoelectronics, and laser physics at ENST and with the Ecole Supérieure d'Optique. Previously, he was a Postdoctoral Fellow supported by both Alcatel Alsthom Research and ENST from 1991 to 1992 . He was an Assistant and then an Associate Professor at ENST from 1992 to 2000. He was with the University of Maryland, College Park, as a Visiting Associate Professor from 1998 to 1999. He joined Opto+, Alcatel Research and Innovation Center, Marcoussis, in October 2000. He is the author or coauthor of more than 150 research papers, eight patents, and is a contributor to book chapters.

Dr. Duan is a member of la Société Française d'Optique. 